\title{
CONSTRUÇÃO DE UM ESPECTRÓGRAFO DE PROJEÇÃO E SUA UTILIZAÇÃO EM DEMONSTRAÇÕES DE ESPECTROSCOPIA ÓPTICA
}

\author{
Eduardo Ribeiro de Azevedo* e Luiz Antônio de Oliveira Nunes \\ Instituto de Física de São Carlos, Universidade de São Paulo, CP 369, 13560-970 São Carlos - SP, Brasil
}

Recebido em 13/2/08; aceito em 11/4/08; publicado na web em 8/10/08

\begin{abstract}
CONSTRUCTION OF A PROJECTION SPECTROGRAPH AND ITS USE IN OPTICAL SPECTROSCOPY CLASSROOMS DEMONSTRATIONS. This article describes a projection spectrograph for use in optical spectroscopy classrooms demonstrations. The apparatus is based on an overhead projector and permits the visualization of several phenomena such as, light dispersion by diffraction gratings, diffraction order, optical fluorescence, continuous and discrete optical emission spectra, and light absorption by liquids and solids. A historical survey about the optical spectroscopy development is also presented.
\end{abstract}

Keywords: projection spectrograph; classrooms demonstrations; optical spectroscopy.

\section{INTRODUÇÃO}

O estudo da interação da radiação com a matéria é uma das formas mais eficazes de se obter informações sobre propriedades microscópicas de sólidos, líquidos e gases. Atualmente, as técnicas espectroscópicas, que são baseadas no estudo da radiação com a matéria, são usadas em diversas aplicações científicas e tecnológicas. Portanto, o entendimento dos conceitos fundamentais envolvidos nos diferentes métodos espectroscópicos é parte fundamental dos currículos de todos os cursos de graduação em Química, Física e em algumas modalidades de Engenharia.

Os experimentos de espectroscopia de luz visível, que utilizam radiação com comprimentos de onda na faixa de 400 a 700 nm, são particularmente importantes devido à sua versatilidade e facilidade de realização. A utilização desses experimentos na caracterização de substâncias está baseada no fato dos níveis de energia dos átomos e moléculas funcionarem como sua impressão digital. ${ }^{1}$ Logo, a observação (determinação dos comprimentos de onda) das raias de emissão e absorção de luz por uma dada substância serve para identificar de maneira inequívoca a composição da mesma. Outras técnicas espectroscópicas ${ }^{2,3}$ (Ressonância Magnética Nuclear e Eletrônica, Fluorescência de raios X, etc.) também permitem a obtenção destas informações, mas para a maioria das aplicações as técnicas ópticas têm maior sensibilidade. Os espectros de absorção e emissão das substâncias podem ser obtidos em uma ampla faixa de comprimentos de onda, sendo mais utilizadas as regiões do infravermelho, entre 0,9 a $25 \mu \mathrm{m}$, e do ultra violeta- visível (UV-Vis), de 250 a $800 \mathrm{~nm}$. Nessas regiões do espectro, os compostos moleculares/atômicos apresentam absorções provenientes de transições de elétrons ligados, vibracionais fundamentais combinadas com sobretons, bandas rotacionais e combinações vibro-rotacionais. ${ }^{2,3}$

Neste artigo, apresentaremos um aparato que pode ser utilizado para demonstrações dos principais conceitos envolvendo espectroscopia de emissão e absorção de luz visível. O aparato foi inspirado no trabalho descrito na ref. 4 baseado na estrutura de um retroprojetor, mas com uma modificação essencial que permite a discussão das emissões discretas de gases atômicos. Além disso, são apresentados detalhes da montagem que permitem a fácil reprodução do equipamento para uso em demonstrações em sala de aula. Utilizando esse

*e-mail: azevedo@ifsc.usp.br aparato, é possível apresentar e discutir concomitantemente conceitos importantes como a dispersão da luz por grades de difração, ordem de difração, fluorescência óptica, espectros ópticos de emissão contínuos e discretos, e absorção de luz por líquidos e sólidos.

\section{Histórico da espectroscopia óptica}

O fenômeno de decomposição da luz é observado na natureza desde a antiguidade (por exemplo, no arco-íris). Em 1665-1666, o físico inglês Isaac Newton utilizou prismas de vidro para demonstrar em laboratório que a luz solar podia ser decomposta em diversas cores e novamente recomposta. ${ }^{5}$ Em linguagem atual, os experimentos de Newton mostraram que a luz branca é constituída por uma distribuição contínua de radiação eletromagnética, e que suas componentes (diferentes cores) podem ser separadas através do fenômeno de refração pelo prisma. ${ }^{6}$ Um outro aspecto que contribuiu para o desenvolvimento da espectroscopia foi a observação da existência de linhas escuras no espectro da luz solar pelo inglês William Hyde Wollaston em 1802. Cerca de 20 anos mais tarde, o físico alemão Joseph von Fraunhofer ${ }^{5}$ "redescobriu" tais linhas escuras enquanto verificava a qualidade dos componentes ópticos que produzia em sua oficina. Fraunhofer utilizou tais linhas escuras como referência de comprimento de onda para a determinação precisa de índices de refração dos vidros que utilizava na construção de prismas e lentes. Ele também percebeu que a observação das linhas escuras podia ser feita de forma mais eficiente utilizando o princípio de difração, que havia sido observado pelo físico italiano Francesco M. Grimaldi. ${ }^{7}$ Assim, em 1820, produziu o primeiro elemento difrativo utilizado para fins espectroscópicos, que era constituído por fios metálicos finos alinhados paralelamente e igualmente espaçados (o que ficou conhecido como grade de difração). Mais tarde, utilizando a tecnologia óptica mais moderna da época (que de fato era produzida por ele mesmo), Fraunhofer identificou 574 linhas escuras no espectro da luz solar. Além disso, observou que a luz proveniente da queima de algumas substâncias apresentava um espectro de emissão com raias discretas, conseguindo medir os comprimentos de onda de duas das linhas de emissão do sódio e chegando a valores próximos dos conhecidos atualmente. ${ }^{8} \mathrm{~A}$ análise espectral da luz emitida através da queima de substâncias com o objetivo de identificar sua composição química ganhou força em 1859, quando os químicos Robert Wilhelm Bunsen e Henry Enfiled Roscoe desenvolveram um queimador a gás onde era possível observar o espectro de absorção ou emissão de uma 
substância quase sem influência do padrão de emissão proveniente da chama. ${ }^{9}$ Mais tarde, trabalhando em conjunto, Bunsen e o físico Gustav Kirchhoff ${ }^{5}$ desenvolveram um espectroscópio e o utilizaram para estudar o espectro de emissão de diversos sais, observando que algumas linhas de emissão coincidiam com linhas escuras que apareciam no espectro da luz do Sol. A partir dessa observação, Bunsen e Kirchhoff realizaram experimentos onde um feixe de luz branca atravessava o gás resultante da queima do sódio e observaram a presença de linhas escuras com os mesmos comprimentos de onda das linhas de emissão. Concluíram, então, que o sódio gasoso emite e absorve luz de mesma energia e que as linhas escuras observadas no espectro solar eram provenientes da absorção pelos diversos gases contidos na atmosfera terrestre e solar. Bunsen e Kirchhoff passaram a utilizar o espectroscópio para identificar elementos químicos e descobriram os elementos césio e rubídio. Um espectroscópio similar ao de Bunsen-Kirchhoff foi utilizado por Pierre J. C. Janssen para analisar as raias, sobrepostas ao espectro contínuo, da luz emitida pelo Sol e atribuiu as mais intensas ao gás hidrogênio. Também estudando o espectro de emissão solar, em 1868 o astrônomo Joseph Norman Lockyer ${ }^{10}$ observou algumas raias que seriam correspondentes a um elemento desconhecido na época, ao qual denominou hélio. Quase 30 anos depois, em 1890, o hélio foi observado na Terra pelo químico escocês William Ramsay. O sucesso dos experimentos de espectroscopia motivou o inglês Henry Joseph Grayson ${ }^{11}$ a produzir, em 1894, a primeira máquina para fabricação de grades de difração, que eram constituídas por riscos micrométricos em vidros, chegando a obter 4700 linhas/mm em 1899. Consolidouse, assim, a espectroscopia óptica como uma técnica para análise da composição qualitativa e quantitativa de substâncias.

Apesar das emissões discretas serem utilizadas para caracterização qualitativa e quantitativa de elementos e substâncias, as origens físicas dessas emissões não eram entendidas. ${ }^{12} \mathrm{O}$ modelo predominante no final do século XIX era o modelo atômico proposto em 1904 por Joseph John Thomson, ${ }^{5}$ no qual se supunha que o átomo era constituído por partículas negativas (elétrons) embebidas em um fluido carregado positivamente que continha a maior parte da massa do átomo. Neste modelo as freqüências discretas de emissão viriam de configurações estáveis, ou seja, de modos normais de vibração cujas frequiências corresponderiam às frequiências de emissão. Porém, este movimento vibratório é necessariamente acelerado, o que causaria a emissão contínua de radiação segundo a teoria eletromagnética de Maxwell, desestabilizando o átomo. Os resultados dos experimentos de espalhamento de partículas $\alpha$ em folhas finas de ouro, realizados por Ernest Rutherford, Hans Geiger, Ernest Marsden ${ }^{5}$ em 1909, mostraram que os átomos não eram "cheios" como no modelo de Thomson, mas do tipo planetário com a carga positiva centrada em um núcleo. No entanto, no modelo planetário o átomo também não seria estável, pois devido ao movimento circular os elétrons emitiriam radiação e perderiam energia até colidirem com o núcleo. Em 1913, o físico dinamarquês Niels Bohr ${ }^{5}$ propôs um modelo para o átomo de hidrogênio que combinava as idéias introduzidas por Marx Planck ${ }^{5}$ (quantização da energia) e Albert Einstein ${ }^{5}$ (luz constituída por fótons) e o átomo planetário de Rutherford. O modelo de Bohr permitiu explicar a razão das linhas discretas de absorção e emissão do átomo de hidrogênio e prever com precisão os comprimentos de onda correspondentes. Neste modelo, Bohr postulou a existência de órbitas estáveis em que os elétrons que possuíam momentum angular igual a um múltiplo inteiro da constante de Planck dividida por $2 \pi$, resultando na quantização de suas energia. Segundo o modelo de Bohr, as emissões atômicas (linhas claras do espectro) ocorrem quando os elétrons fazem transições de uma órbita de maior energia para uma de menor energia e as absorções (linhas escuras do espectro) correspondiam a transições entre órbitas de menor para maior energia. Apesar do sucesso quantitativo do modelo de Bohr na explicação dos espectros de átomos hidrogenóides, este modelo era baseado no postulado específico das órbitas estáveis e era por isso insatisfatório. Em 1925 e 1926, os físicos Werner Karl Heisenberg ${ }^{5}$ e Erwin Rudolf Josef Alexander Schrödinger ${ }^{5}$ propuseram, independentemente, novas formulações da Mecânica, que ficaram conhecidas como "quânticas" e se tornaram o novo paradigma na Física. A formulação mais conhecida da Mecânica Quântica é a baseada na Equação de Schrödinger acompanhada de um conjunto de postulados fundamentais que diferem dos da Mecânica Clássica. A utilização da Mecânica Quântica permitiu, dentro dessa nova visão, o entendimento das propriedades atômicas e moleculares, tais como emissão, absorção, ligação química, potenciais de ionização, polarização atômica, magnetismo atômico e nuclear, etc.. ${ }^{3}$ Neste contexto, a união entre a Espectroscopia Óptica e a Mecânica Quântica é fundamental, pois enquanto a espectroscopia permite medir com precisão as emissões e absorções das substâncias, a mecânica quântica permite a elaboração de modelos que correlacionem essas medições com propriedades microscópicas das moléculas e átomos que constituem essas substâncias.

\section{DESCRIÇÃO DO APARATO}

A realização da maioria dos experimentos de espectroscopia óptica requer quatro elementos básicos: uma fonte de luz, um colimador, um elemento que produza a decomposição da luz (prisma ou grade de difração) e um detector (olho humano, sensor fotoelétrico e sensor fotovoltáico). O aparato apresentado neste artigo é baseado na estrutura de um retroprojetor convencional, tal como mostrado na Figura 1 (ver também Figura $1 \mathrm{~S}$ do material suplementar). Uma das lâmpadas de tungstênio do retroprojetor foi utilizada como fonte de luz branca, sendo a lâmpada reserva substituída por uma lâmpada de vapor de mercúrio comercial de $250 \mathrm{~W}$ para servir como fonte de luz com emissão discreta. O sistema mecânico de substituição das lâmpadas de tungstênio do retroprojetor foi modificado para permitir o intercâmbio automático entre as lâmpadas (tungstênio e mercúrio), Figura 1b. O bulbo da lâmpada de mercúrio foi removido para permitir a observação das raias sem a influência da luz branca gerada pelo material fosforescente. A lâmpada de mercúrio foi acondicionada em um tubo cilíndrico de vidro comum com diâmetro de $\sim 50 \mathrm{~mm}$ e parede de $\sim 2 \mathrm{~mm}$ para diminuir a emissão de radiação ultravioleta e para proteger o operador de eventuais curtos circuitos. O reator da lâmpada de mercúrio foi adaptado na parte interna do retroprojetor, como mostrado na Figura 1b. A ventilação do retroprojetor foi reforçada através da substituição do ventilador por outro de maior potência. Para produzir um feixe paralelo de luz foi construída uma fenda de alumínio que deve ser posicionada acima da lente de Fresnel do retroprojetor, Figura 1a, e cuja largura pode ser regulada continuamente. Como elementos de decomposição da luz foram utilizadas grades de difração de transmissão com 300 e 600 linhas/ $\mathrm{mm}$. Fontes para aquisição dessas grades de difração são as empresas Pasco e Phywe instrumentos educacionais. A grade de difração deve ser posicionada na parte superior da lente de focalização situada no braço do retroprojetor, Figura 1a. O ajuste do foco pode ser feito como em um retroprojetor convencional, i.e., observando-se a imagem da fenda na tela de projeção.

O aparato desenvolvido é suficientemente robusto para ser transportado e permite o rápido intercâmbio entre as lâmpadas. Entretanto, caso haja dificuldades para implementar as modificações sugeridas, pode-se inserir uma lâmpada de mercúrio (sem a remoção do bulbo) no interior do projetor, mantendo o reator e as devidas conexões elétricas na parte externa. A fenda de alumínio também pode ser substituída por duas folhas de papel cartão pretas dispostas paralelamente. Na ausência de reforço da ventilação deve-se ter cuidado para não haver sobre aquecimento do sistema. 


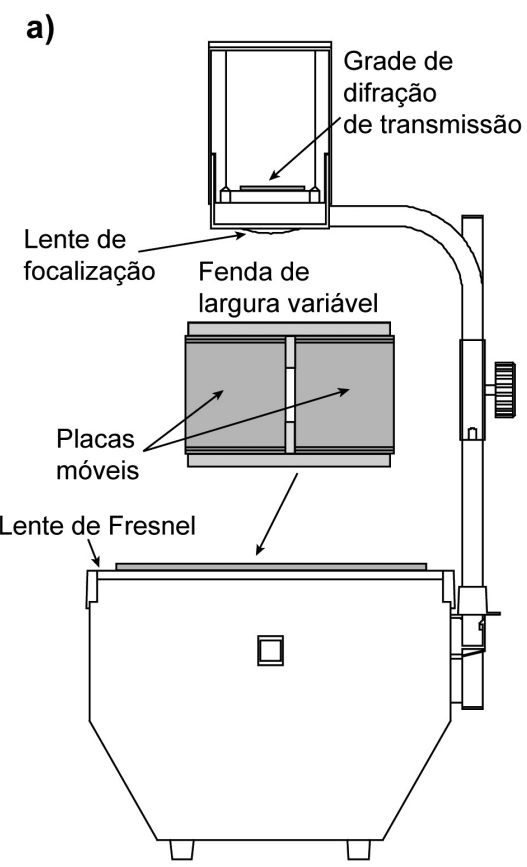

Um aspecto crítico do experimento é que o feixe de luz correspondente à ordem zero deve ser perpendicular à tela de projeção. Isso pode ser conseguido ajustando-se o sistema para que linhas correspondentes à mesma ordem de difração, mas com sinais opostos, apareçam simetricamente dispostas em relação à ordem zero.
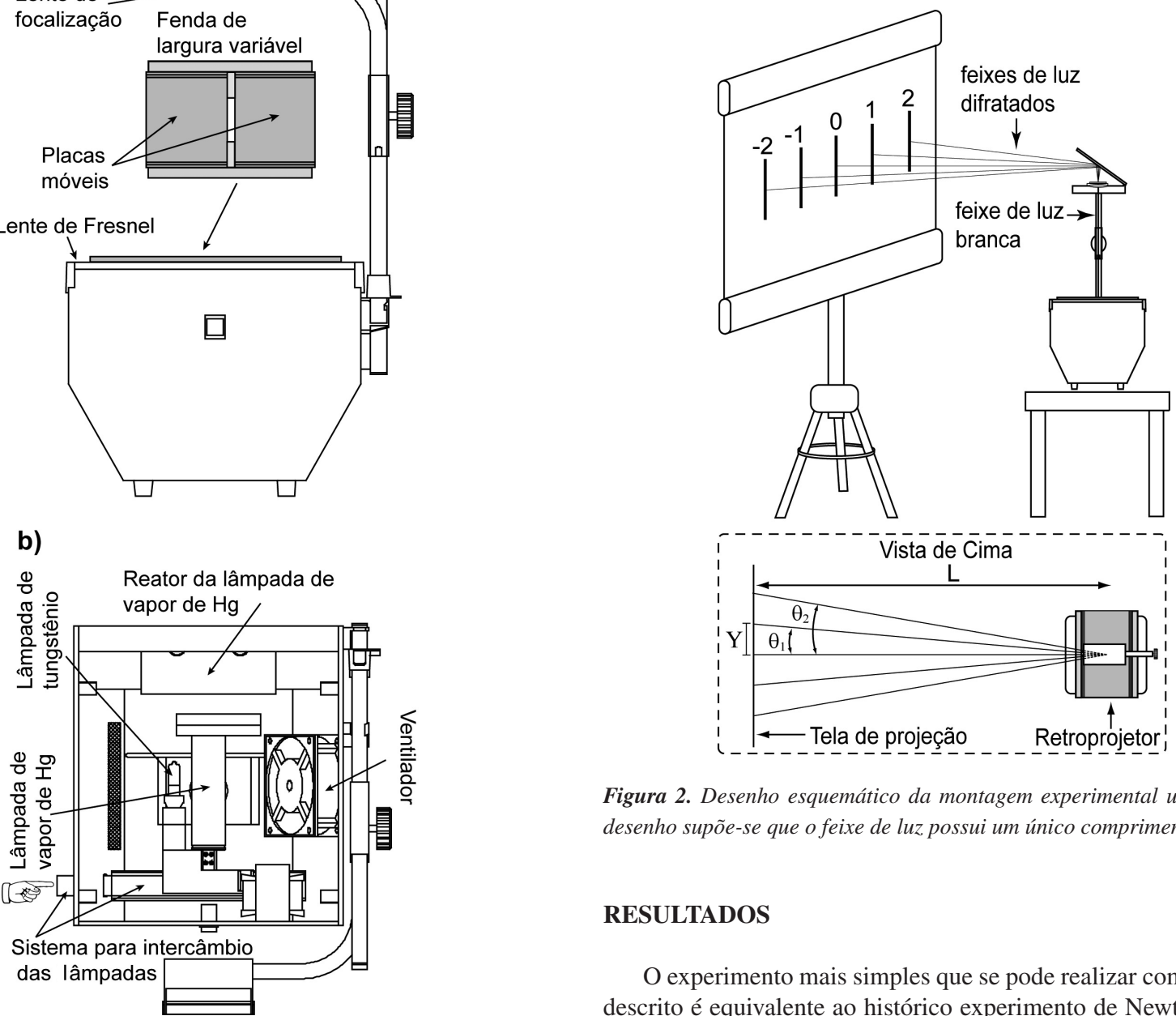

Figura 1. a) Desenho esquemático da vista lateral do retroprojetor com a fenda de largura variável evidenciada. b) Corte transversal (visto de cima) do interior do retroprojetor. (Ver fotografia do retroprojetor modificado na Figura $1 S$ do material suplementar)

\section{EXPERIMENTOS}

Na Figura 2 está mostrado um esquema geral dos experimentos. A luz emitida pela lâmpada é colimada pela fenda e incide na grade de difração. O feixe de luz é então disperso pela grade, sendo refletido pelo espelho plano do retroprojetor e projetado na tela localizada a uma distância de aproximadamente $3 \mathrm{~m}$ da grade de difração. Conhecendo-se a distância grade-tela (L) e medindo-se a distância $\left(\mathrm{Y}_{1}, \mathrm{Y}_{2}, \ldots, \mathrm{Y}_{n}\right)$ das diferentes ordens de difração em relação à ordem zero (projeção da fenda na tela), determinam-se os ângulos de difração $\theta_{1}, \theta_{2}, . ., \theta_{n}$ para as diferentes ordens $n .{ }^{6}$ Utilizando esses ângulos e o número de linhas $/ \mathrm{mm}$ da grade de difração, os comprimentos de onda $\lambda_{i}$ presentes na luz incidente são determinados utilizando a Equação:

$n \lambda_{i}=d \operatorname{sen} \theta_{n} ; n=0,1,2,3, \ldots$

onde d é a separação entre as ranhuras da grade de difração.

Figura 2. Desenho esquemático da montagem experimental utilizada. No desenho supõe-se que o feixe de luz possui um único comprimento de onda

\section{RESULTADOS}

O experimento mais simples que se pode realizar com o aparato descrito é equivalente ao histórico experimento de Newton (porém usando grade de difração ao invés de prisma), isto é, a visualização da decomposição da luz branca proveniente da lâmpada de filamento de tungstênio. Utilizando-se uma grade de difração de 600 linhas/ $\mathrm{mm}$ posicionada a $3 \mathrm{~m}$ da tela de projeção e abertura da fenda de $\sim 5 \mathrm{~mm}$, obtém-se o padrão mostrado na Figura 3, onde se observa a decomposição da luz branca em um contínuo de comprimentos de onda para as ordens de difração 1 e -1 . Utilizando a Equação 1 pode-se determinar os limites de comprimento de onda que o olho humano é capaz de detectar, ou seja, a faixa de comprimentos de onda correspondente à luz visível. Com os valores de $\mathrm{Y}$ correspondentes ao início do vermelho e final do azul mostrados na Tabela 1, este limite foi estimado como sendo de $\sim 410$ a $680 \mathrm{~nm}$.

Substituindo a lâmpada de filamento de tungstênio pela lâmpada de vapor de mercúrio observa-se o padrão mostrado na Figura 4a, o qual apresenta um conjunto de raias discretas diretamente associadas às transições entre os diferentes níveis de energia do gás $\mathrm{Hg}$. A olho nu observam-se três raias intensas de emissão com cores laranja, verde e azul, além de uma raia de baixa intensidade entre as linhas verde e azul (esta linha não aparece na fotografia da Figura 4a devido à sensibilidade da máquina fotográfica). Na Tabela 2 estão mostrados os valores de $\mathrm{Y}$ medidos e os correspondentes comprimentos de onda calculados para as linhas de cores laranja, verde e azul. Comparando-se os comprimentos de onda extraídos do experimento com aqueles reportados na literatura, ${ }^{13}$ o erro cometido foi inferior a $1 \%$. Diminuindo-se a 


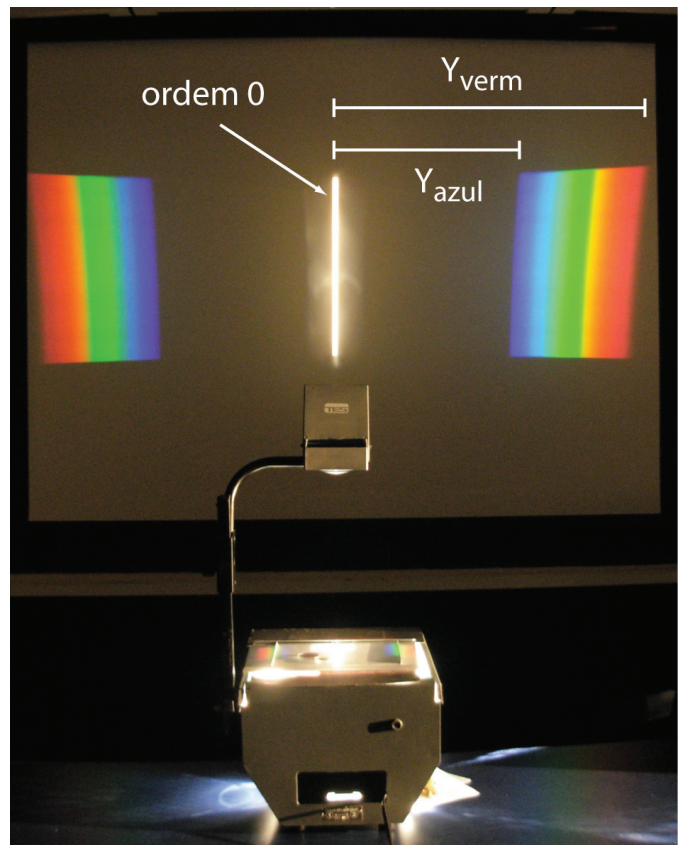

Figura 3. Fotografia mostrando a decomposição da luz branca (lâmpada de tungstênio original do retroprojetor). Distância $L=3 \mathrm{~m}$ e grade de difração de 600 linhas/mm. A curvatura apresentada pelo padrão deve-se à aberração esférica na lente de focalização do retroprojetor

Tabela 1. Medida da faixa de comprimentos de onda detectável pelo olho humano

\begin{tabular}{lcc}
\hline Cor observada & $\mathrm{Y}(\mathrm{cm})$ & $\lambda_{\text {medido }}(\mathrm{nm})$ \\
\hline Início do azul & $\mathrm{Y}_{\text {azul }}=80$ & 429 \\
Final do vermelho & $\mathrm{Y}_{\text {vermelho }}=130$ & 662 \\
\hline
\end{tabular}

largura da fenda para $1 \mathrm{~mm}$, pôde-se também observar que a linha de cor laranja é de fato um dubleto, cuja separação medida na tela foi de $0,5 \mathrm{~cm}$, correspondente a uma separação de $2 \mathrm{~nm}$ em comprimento de onda. Assim, neste experimento, conceitos importantes como quantização dos níveis de energia atômicos e a sua relação com o surgimento da Mecânica Quântica podem ser discutidos.

Na Figura 4b está mostrado o padrão projetado quando é utilizada uma grade de difração de 300 linhas $/ \mathrm{mm}$. Neste caso, as linhas de segunda ordem de difração $(n=2)$ também aparecem projetadas na tela, sendo evidente que a separação entre elas é o dobro que em primeira ordem. Além disso, observa-se que para segunda ordem a intensidade das linhas é consideravelmente menor, mostrando que, embora a observação das linhas de segunda ordem seja vantajosa em termos de aumento de resolução, há uma considerável perda de intensidade. Os comprimentos de onda determinados neste caso estão mostrados na Tabela 3. Analisando os resultados mostrados na Tabela 3, observa-se que o erro percentual é sistematicamente maior para as medidas referentes à primeira ordem, o que advém da menor precisão relativa na medida das distâncias. Portanto, aqui os principais conceitos envolvidos no fenômeno de difração e interferência óptica, como dependência com o comprimento de onda e espaçamento entre as ranhuras da grade, podem ser discutidos. Note também que o conceito de resolução espectral e sua dependência com o número de linhas iluminadas na grade de difração, distância entre a grade ou a tela de projeção e com a largura da fenda também podem ser tratados. Isso pode ser feito em um contexto histórico, já que foi este tipo de melhora tecnológica que levou à observação da estrutura fina dos
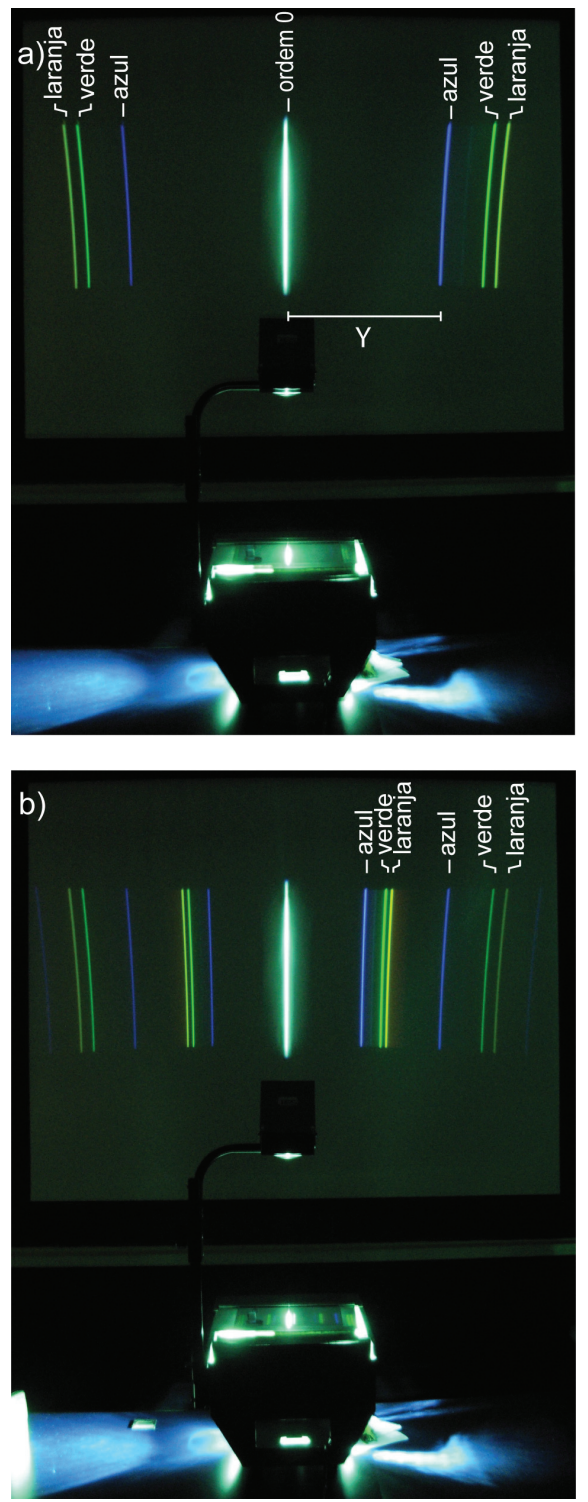

Figura 4. Fotografias mostrando a decomposição da luz proveniente da lâmpada de vapor de Hg adaptada ao retroprojetor. a) Utilizando uma grade de difração de 600 linhas $/ \mathrm{mm}$. b) Utilizando uma grade de difração de 300 linhas $/$ mm. A curvatura apresentada pelas linhas deve-se à aberração esférica na lente de focalização do retroprojetor. A diferença de intensidade entre as ordens positivas e negativas deve-se ao fato da grade de difração ser construída para privilegiar um delas (ângulo de blaze)

Tabela 2 . Medida dos comprimentos de onda referentes às raias de emissão de uma lâmpada de vapor de mercúrio - fenda de $5 \mathrm{~mm}$ grade 600 linhas $/ \mathrm{mm}$

\begin{tabular}{|c|c|c|c|c|}
\hline Cor observada & $\mathrm{Y}(\mathrm{cm})$ & $\lambda_{\text {medido }}(\mathrm{nm})$ & $\lambda_{\text {esperado }}(\mathrm{nm})^{13}$ & Erro (\%) \\
\hline laranja & 111,5 & 581 & 578,02 & 0,4 \\
\hline verde & 105,0 & 551 & 546,07 & 0,8 \\
\hline$\underline{\text { azul }}$ & 82,0 & 439 & 435,84 & 0,8 \\
\hline
\end{tabular}

espectros de átomos de muitos elétrons e ao conseqüente declínio do modelo de Bohr como modelo geral para a estrutura atômica.

Outro aspecto que pode ser discutido utilizando-se o padrão da lâmpada de mercúrio é o conceito de fluorescência óptica. O gás de mercúrio excitado apresenta várias raias de emissão, das quais muitas, mesmo que intensas, não são observadas a olho nu, pois se encontram 
Tabela 3. Medida dos comprimentos de onda referentes às raias de emissão de uma lâmpada de vapor de mercúrio - fenda de $5 \mathrm{~mm}$ grade 300 linhas $/ \mathrm{mm}$

\begin{tabular}{lclccc}
\hline $\begin{array}{l}\text { Cor } \\
\text { observada }\end{array}$ & $\begin{array}{c}\text { Ordem de } \\
\text { Difração }\end{array}$ & $\mathrm{Y}(\mathrm{cm})$ & $\begin{array}{c}\lambda_{\text {medido }} \\
(\mathrm{nm})\end{array}$ & $\begin{array}{c}\lambda_{\text {esperado }} \\
(\mathrm{nm})^{13}\end{array}$ & Erro $(\%)$ \\
\hline laranja & 1 & 53,5 & 585 & 578,02 & 1,2 \\
verde & 1 & 50,2 & 550 & 546,07 & 0,7 \\
azul & 1 & 40 & 440 & 435,84 & 1,0 \\
laranja & 2 & 112,0 & 583 & 578,02 & 0,9 \\
verde & 2 & 105,0 & 551 & 546,07 & 0,8 \\
azul & 2 & 82,0 & 439 & 435,84 & 0,8 \\
\hline
\end{tabular}

na região do ultravioleta (UV) e do infravermelho (IR). Um artifício para se observar algumas das raias de emissão na região do UV é através do processo de fluorescência. A fluorescência ocorre quando excitamos um material com alta energia e observamos sua emissão em uma energia menor, isto é, a luz emitida tem maior comprimento de onda que a absorvida pelo material. Algumas substâncias empregadas no clareamento de papel sulfite apresentam este fenômeno. Na Figura 5 está mostrado o padrão obtido para a lâmpada de mercúrio, onde se colocou uma folha de papel sulfite na região tracejada. Observa-se claramente o aparecimento de uma linha adicional na região iluminada do papel, a qual se deve à fluorescência, ou seja, moléculas impregnadas no papel absorvem radiação UV, invisível ao olho humano, e emitem luz visível de coloração azulada. O comprimento de onda medido para esta linha foi de $406 \mathrm{~nm}$ (fluorescência 1 na Tabela 4), o que corresponde à região de baixa sensibilidade do olho. Note que a cor azul apresentada pela linha em $406 \mathrm{~nm}$ se deve somente ao fato do alvejante utilizado no papel apresentar florescência com essa cor, não havendo, portanto, nenhuma relação entre a cor e o comprimento de onda medido neste caso. Além da linha de fluorescência correspondente à excitação em $406 \mathrm{~nm}$, é possível também observar a olho nu uma segunda linha (fluorescência 2 na Tabela 4) correspondente à excitação em $368 \mathrm{~nm}$. No entanto, devido à absorção pelos vários componentes ópticos neste comprimento de onda (lente de Fresnel, placa de vidro, lente de focalização), a intensidade desta linha, quando projetada na tela, é bastante reduzida não podendo ser fotografada.

Outra demonstração que pode ser realizada com o aparato apresentado é a observação do espectro de transmissão de compostos

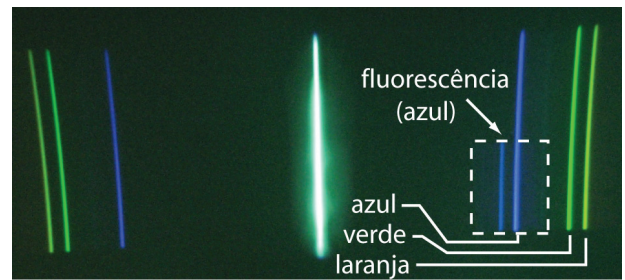

Figura 5. Fotografias mostrando a raia devido à fluorescência de uma folha de papel sulfite. A região onde foi colocada a folha de papel está indicada pelo retângulo tracejado. Distância $L=3 \mathrm{~m}$ e grade de difração de 600 linhas/ mm. A curvatura apresentada pelas linhas deve-se à aberração esférica na lente de focalização do retroprojetor

Tabela 4. Medida dos comprimentos de onda referentes a duas raias de fluorescência lâmpada de vapor de mercúrio - fenda de $5 \mathrm{~mm}$ grade 600 linhas/mm

\begin{tabular}{|c|c|c|c|c|}
\hline Cor observada & $\mathrm{Y}(\mathrm{cm})$ & $\lambda_{\text {medido }}(\mathrm{nm})$ & $\lambda_{\text {esperado }}(\mathrm{nm})^{13}$ & Erro $(\%)$ \\
\hline Fluorescência 1 & 75,5 & 407 & 404,66 & 0,5 \\
\hline Fluorescência 2 & 68,0 & 368 & 365,01 & 0,9 \\
\hline
\end{tabular}

líquidos ou sólidos transparentes coloridos. ${ }^{14}$ Para tal foram utilizadas a lâmpada de filamento de tungstênio e a grade de 600 linhas/ $\mathrm{mm}$. O material que se deseja analisar deve ser posicionado sobre a fenda variável. Na Figura 6 está mostrado o padrão de transmissão observado para um filtro com transmissão no azul e no vermelho (filtro 1), uma solução aquosa de $\mathrm{NdCl}_{3}$ e um filtro com transmissão na região do vermelho (filtro 2). Na Tabela 5 estão apresentados os comprimentos de onda medidos para três linhas de absorção do $\mathrm{NdCl}_{3}$, juntamente com os comprimentos de onda medidos em um espectrofotômetro comercial. A diferença entre os valores medidos com o espectrofotômetro comercial e o aparato apresentado é inferior a $2 \%$. Convém acrescentar que a observação dos espectros de transmissão pode ser também realizada com materiais mais comuns, como anilina e papel celofane.

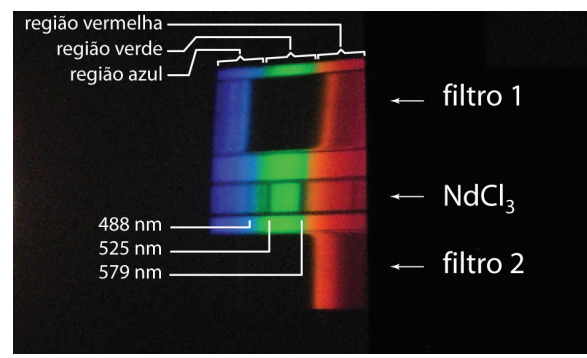

Figura 6. Fotografia mostrando o espectro de transmissão de uma solução aquosa de $\mathrm{NdCl}_{3}$ e de dois filtros dielétricos com transmissão nas regiões do azul e do vermelho (filtro 1) e do vermelho (filtro 2), respectivamente. No espectro de transmissão da solução de $\mathrm{NdCl}_{3}$ a linha de absorção na região do vermelho não foi medida, pois não pode ser observada a olho nu

Tabela 5. Medida dos comprimentos de onda de absorção da solução de $\mathrm{NdCl}_{3}$

\begin{tabular}{llccc}
\hline Cor observada & $\mathrm{Y}(\mathrm{cm})$ & $\lambda_{\text {medido }}(\mathrm{nm})$ & $\lambda_{\text {esperado }}(\mathrm{nm})$ & Erro $(\%)$ \\
\hline azul esverdeado & 92 & 488 & 487 & 0,4 \\
verde & 99,5 & 525 & 523 & 0,4 \\
laranja & 111,0 & 579 & 576 & 0,5 \\
\hline
\end{tabular}

\section{CONCLUSÃO}

Neste artigo foram descritas a construção e a utilização de um espectrógrafo de projeção baseado em um retroprojetor. Mostrou-se que o aparato permite a realização de demonstrações qualitativas e quantitativas do fenômeno de difração da luz e espectroscopia de emissão e absorção de luz visível. Especificamente, foram demonstradas a decomposição espectral da luz proveniente de lâmpadas de filamento de tungstênio (espectro contínuo) e de vapor de mercúrio (espectro discreto); a fluorescência no visível devido à excitação no UV do gás de mercúrio; a influência do número de linhas das grades de difração nos espectros; a influência da largura da fenda na resolução espectral e, a absorção de luz por filtros ópticos e por uma solução de $\mathrm{NdCl}_{3}$. Os resultados quantitativos apresentados incluem a determinação da faixa de comprimentos de onda que o olho humano é capaz de detectar, a medida dos comprimentos de onda correspondentes à emissão do gás mercúrio, incluindo algumas das linhas no UV (visualizadas através do processo de fluorescência), e a determinação dos comprimentos de onda correspondentes a algumas raias de absorção de uma solução aquosa do $\mathrm{NdCl}_{3}$. Embora tenham sido realizados em condições típicas de sala de aula, i.e, sem nenhum cuidado especial além do correto alinhamento do sistema, os resultados obtidos apresentaram erros inferiores a $2 \%$ quando comparados com valores reportados na literatura. 


\section{MATERIAL SUPLEMENTAR}

Em http://quimicanova.sbq.org.br, com acesso livre e em formato PDF, está disponível a Figura 1S, que mostra fotos do equipamento construído.

\section{AGRADECIMENTOS}

Aos técnicos J. A. de Castro Filho, S. Alvarez, E. Santoni pelo apoio técnico e aos Profs. G. F. L. Ferreira, G. Costa, T. J. Bonagamba, A. Magalhães, J. Teles e M. C. Terrile pelas críticas, comentários e sugestões.

\section{REFERÊNCIAS}

1. Filgueiras, C. A. L.; Química Nova na Escola 1996, n. 3, 22.

2. Skoog, D.; Holler, F.; Nieman, T. ; Principles of Instrumental Analysis, $5^{\text {th }}$ ed., Saunders College Publishing: Orlando, 1992.
3. Atkins, P.; Physical Chemistry, $6^{\text {th }}$ ed., Oxford University Press: Oxford, 2001.

4. Sadler, P.; The Physics Teacher 1991, 29, 422.

5. Cropper, W. H.; Great Physicists, $1^{\text {st }}$ ed., Oxford University Press: Oxford, 2001.

6. Tipler, P.; Física - Eletricidade e Magnetismo - Ótica, 4a ed., Livros Técnicos e Científicos: Rio de Janeiro, 2000.

7. The Columbia Encyclopedia, $6^{\text {th }}$ ed., Columbia University Press, 2004.

8. Sala, O.; Quim. Nova 2007, 30, 2057.

9. Jensen, W.; J. Chem. Educ. 2005, 82, 518.

10. Meadows, A.; Science and Controversy, $1^{\text {st }}$ ed., MIT Press: Cambridge, 1972.

11. Bolton, H.; Australian Dictionary of Biography, $1^{\text {st }}$ ed., Melbourne University Press: Melbourne, 1983.

12. Sala, O.; Quim. Nova 2007, 30, 1773.

13. http://physics.nist.gov/PhysRefData/Handbook/Tables/mercurytable2. htm, acessada em Fevereiro 2008.

14. Brecher, K.; The Physics Teacher 1991, 29, 454. 


\section{CONSTRUÇÃO DE UM ESPECTRÓGRAFO DE PROJEÇÃO E SUA UTILIZAÇÃO EM DEMONSTRAÇÕES DE ESPECTROSCOPIA ÓPTICA}

Eduardo Ribeiro deAzevedo* e Luiz Antônio de Oliveira Nunes

Instituto de Física de São Carlos, Universidade de São Paulo, CP 369, 13560-970 São Carlos - SP, Brasil
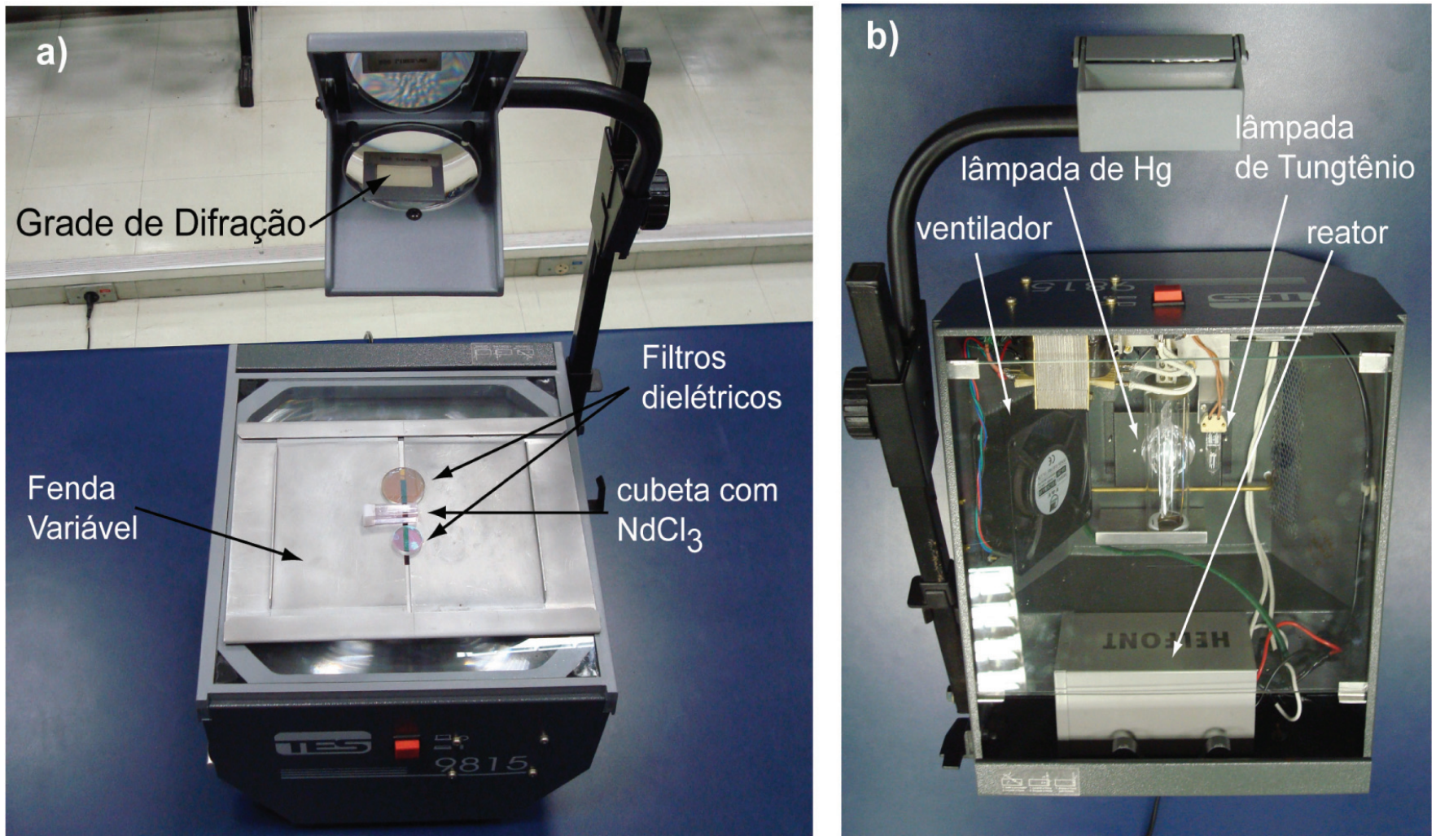

Figura 1S. a) Fotografia mostrando o retroprojetor em uma configuração típica de observação dos espectros de transmissão. b) Figura do interior do retroprojetor, enfatizando as modificações realizadas 